\title{
Local artistic style formation in urban environment design
}

\author{
Sergey Mikhailov ${ }^{1[0000-0002-4306-7948]}$, Aleksandrina Mikhailova ${ }^{1 *[0000-0002-2238-5189]}$, \\ NeilNadyrshine ${ }^{1[0000-0002-6029-0092]}$, DmitryKoshkin ${ }^{1[0000-0001-6787-0957]}$, and DanilaEgorov ${ }^{1[0000-}$ \\ 0002-5926-8293] \\ ${ }^{1}$ Kazan State University of Architecture and Engineering, 420043, Zelenayast., Kazan, Russia
}

\begin{abstract}
The article presents the corporate style as the leading project method in design in XXth century and its use in the design of the urban environment in the form of a local architectural and artistic style of the ensemble. It has become widespread in the organization of pedestrian streets in urban centers as a means of stylistic harmonization of diverse buildings and increasing the artistic expressiveness of the spatial ensemble. The striking example is the reconstruction of the Nikolayviertel in Berlin and his development into a territorial brand. At the same time, the graphic, artistic and stylistic accompaniment of the territorial brand became a logical continuation and development of its local architectural and artistic style, embedded in the architectural context, enhancing its imaginative component and the general artistic «positive». The modern post-industrial society brings with it changes that have affected the artistic and aesthetic qualities of the environment. Instead of an «open-air museum» with a clearly organized historical and architectural exposition, the visitor is offered a «settled» and a little shabby in the «shabby chic» style urban environment with picturesque green corners of cafes and restaurants.

Keywords:urban environment design, territorial branding, local architectural and artistic style, corporate ID, visual identification, Nikolayviertel pedestrian street.
\end{abstract}

\section{Introduction}

The concept of «corporate identity» (corporate ID) appeared in the 1960s and 1970s in the professional language of Russian designers as a derivative from English «design coordination and corporate image». The well-known design theorist Vyacheslav Glazychev defined the corporate identity (corporate ID) as «a set of visually perceived features that cause a stable stereotype of a particular industrial or trading company in the consumer. «He associated the emergence of corporate identity with the activities of the famous German artist and architect Peter Behrens. As the artistic director of the AEG company (19071909), he first made an attempt to form an expressed face of the company among other industrial companies on the basis of uniform artistic and stylistic principles of shaping, a wide range of objects - from the company's logo, graphics of its documentation and

* Corresponding author:misuoka@gmail.com 
advertising, external type of products to the architecture of industrial buildings and trade representations. At the same time, V. Glazychev identified the phenomenon of corporate identity with the beginning of industrial design in general (calling it a «hidden definition of design») and linked this process with monopoly capitalism [1].

The term «urban design», as noted by University of Sydney professor Jon Lang, appeared in the 1950s [2]. Initially it was used to denote subject forms (objects of subject design) intended for urban spaces. At the same time, the presence of the word «design» in this term referred to the industrial methods of manufacturing objects and their serial production. The concept of «urban environment design» became widespread in the second half of XXth century. This is largely due to the widespread construction in the process of post-war reconstruction of pedestrian streets and zones in many European cities, which became the embodiment of ideas about the ideal city of the XXth century, the first prototypes of highly comfortable urban spaces, organized mainly by means of design. The question posed at that time about the comfort of urban spaces does not lose its relevance till now in the field of streets, parks and houses $[3,4]$ vertical urbanism and other innovations $[5,6]$, as well as questions about what urban design is, what are its goals and objectives [7, 8]. Moreover, their relevance increases with the organization of microspaces in the environment of a post-industrial city, which is considered as a complex spatial and social phenomenon, the place of activity of citizens [9]. Design theorists describe the principle of ergocentrism which expands the boundaries of ergonomics to its macro level - «ergonomics of space» $[9,10]$. At the same time, they refer to various categories of urban design: «overall urban design», «integrated urban design», «plug-in urban design», «piece-by-piece urban design» [11]. Modern researchers are especially interested in how art and culture are integrated into the urban environment $[12,13]$ its details [14], their interaction with urban design as a special kind of art [15] in organizing open public spaces of the city [16, 17], designing a children's play environment $[18,19]$ having common features with architecture, landscape architecture, interior and garden design [15, 20, 21]. The design of the urban environment today is almost impossible to imagine without digital technologies and postindustrial robotics [22], without creating models of urban design for a smart city using artificial intelligence $[23,24]$, at the same time the task to preserve cultural identityis important $[25,26]$.

\section{Research methods}

Research object. The object of the research is the design coordination and corporate image as the leading design method in the design of XXth century and the peculiarities of its use and development in the design of the urban environment in the form of a local architectural and artistic style of the ensemble, and then territorial branding. The work is based on materials collected by the authors in the course of field studies of pedestrian zones in European cities.

Research methods. The research methodology was based on a systematic approach, which made it possible to consider the phenomena in their relationship as an integral part of a single whole and using the following methods:

- the historical and genetic method, which made it possible to trace in the historical aspect the evolution of the method of local artistic style formation in the design of the urban environment first half XXth - beginning of XXIst centuries;

- method of comparative analysis - for differentiation and qualitative assessment of the studied phenomena and their manifestations;

- generalization of historical and modern domestic and foreign experience in the field of artistic style education in city design. 


\section{Results and Discussion}

«Corporate identity» (corporate ID) as the leading design method in the design of the XXth century. Since the $70 \mathrm{~s}$ of the last century, such concepts as «corporate identity», «visual identification», «corporate style» have become one of the key concepts in industrial design, largely determining its design methodology. At this time, the topic of identification began to be considered by researchers in various aspects: identification of the subject-object in idealistic philosophy, as self-identification in psychoanalysis and personal psychology, as group identification in sociology and political science, and, ultimately, as the identification of companies in the economic space. Corporate identity got widespread and defined the whole ideology of the industrial design of the twentieth century, «concentrating a major problem, the contradictions, the goals and values of his design culture» [27]. As the research shows, four main stages can be distinguished in the development of corporate identity in the design of the XXth century.

\subsection{The first stage is the beginning of XXth century. The emergence of the first corporate identity in the conditions of monopoly capitalism}

The artistic program for the AEG firm by Peter Behrens (1907-1910) is one of the first examples of corporate identity in the history of design, which anticipated almost all of its main structural and systemic features as the entire design ideology of 20th century modernism (Fig.1). The AEG corporate identity was developed as a complex system of organizing the whole and is represented by the marketing and artistic concept of products, the advertising image of the product, a new corporate ideology, a project for the modernization of production and technology, a new business program [27].

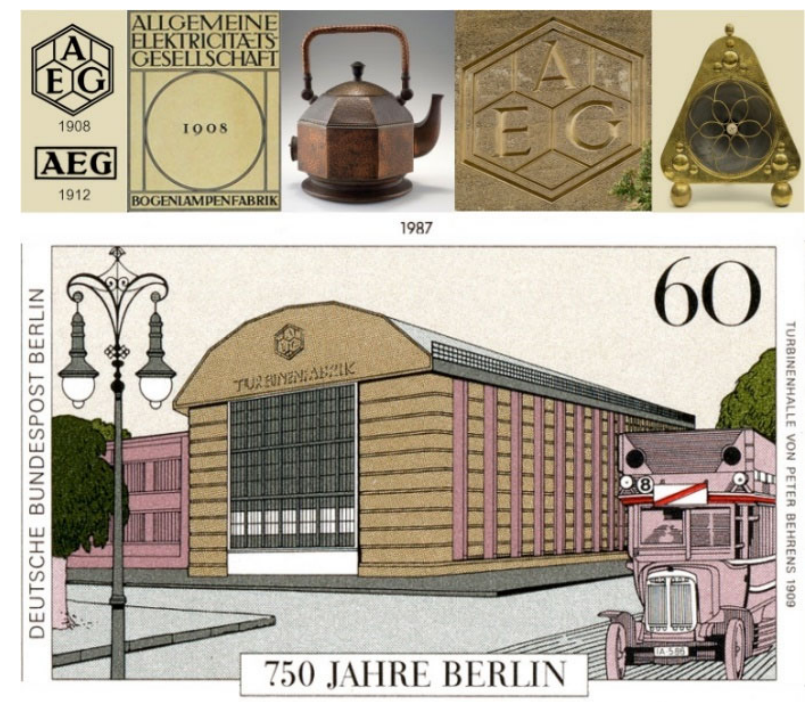

Fig. 1. $1^{\text {st }}$ stage: the beginning of XXth century. The emergence of the first corporate identity in the conditions of monopoly capitalism. The artistic program for the AEG firm by Peter Behrens.

\subsection{The second stage is the mid. XXth century. Corporate identity as a widespread area of design activity in industrial design}

In the 1950-60s in the context of dynamic economic development and heightened market competition, corporate identity is becoming widespread, becoming a powerful tool in 
solving socio-economic problems. At this time, a special graphic language of corporate styles, the composition and principles of the graphic construction of their elements are formed. The «pictorial» trademarks of companies are being replaced by abstract forms and compositions reflecting the aesthetics of functionalism. At this stage, corporate identity programs are developed for large companies and were designed to ensure: the continuity of the style of the firm; popularization of new products; mutual support of products due to their common style; rationalization of production; streamlining and improving the organization of production (Fig.2).

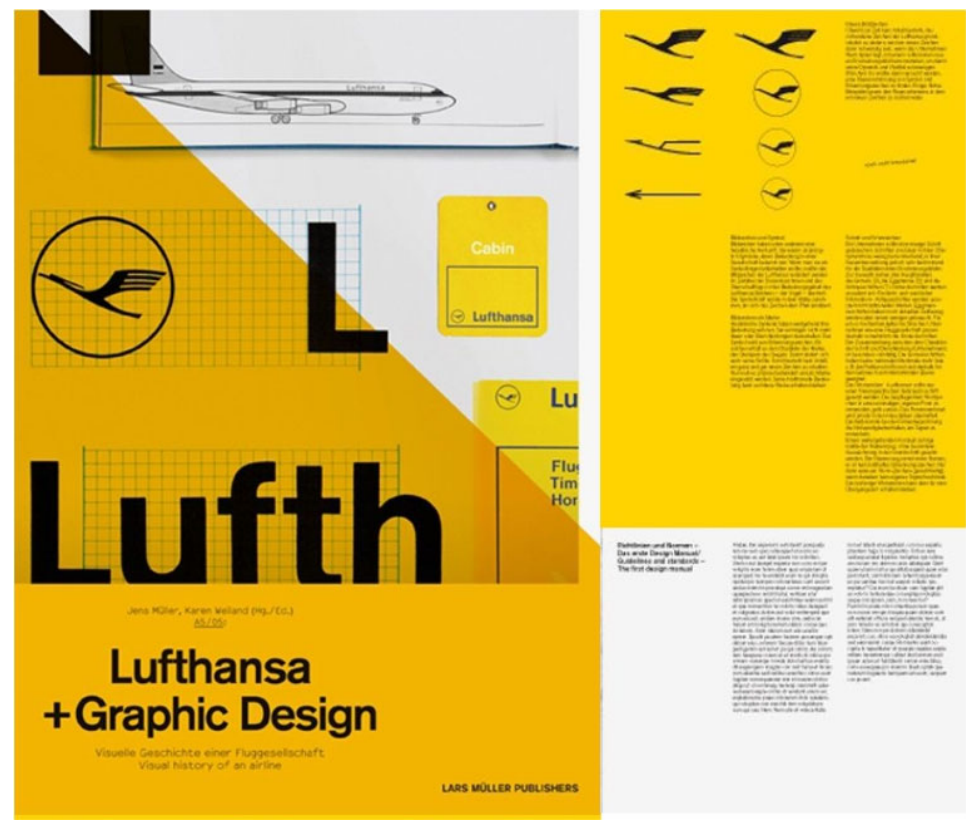

Fig. 2.2 ${ }^{\text {nd }}$ stage: the mid. XXth century. Corporate identity as a widespread area of design activity in industrial design. Lufthansa - Designed by OtlAicher - Ulm, 1962.

\subsection{The third stage is the second half XXth century. Corporate identity as a universal project design method}

In the late 1970s and 1980s an increase in the artistic component takes place in the general methodology for the development of corporate styles, turning them into a separate design tool (method) in solving architectural and artistic problems. Corporate styles as a project method, in particular, are being developed in the conditions of planned management and state design of socialist countries, where at that time an unprecedented situation of creating corporate identity programs for entire industries is developed. In the absence of market competition, the method of corporate styles here more and more acquired the form of an artistic and stylistic program of shaping, solving, first of all, the tasks of the aesthetic and culturological plan. The logical conclusion was the theory of corporate identity of AllRussian Research Institute of Technical Aesthetics (VNIITE) in the form of a "design program», which includes not only the formulation of the design and artistic concept of a complex system object, but also the development of an organizational program that ensures the implementation of this concept, including the design of the facility and the implementation of the project in industry(Fig.3).

A definite culmination in the development of corporate identity as a universal design method of aesthetic organization of multidisciplinary complexes was its use in city design 
as a local architectural and artistic style of an urban ensemble, as well as temporary corporate styles of major exhibitions, fairs, sports and social and political events.

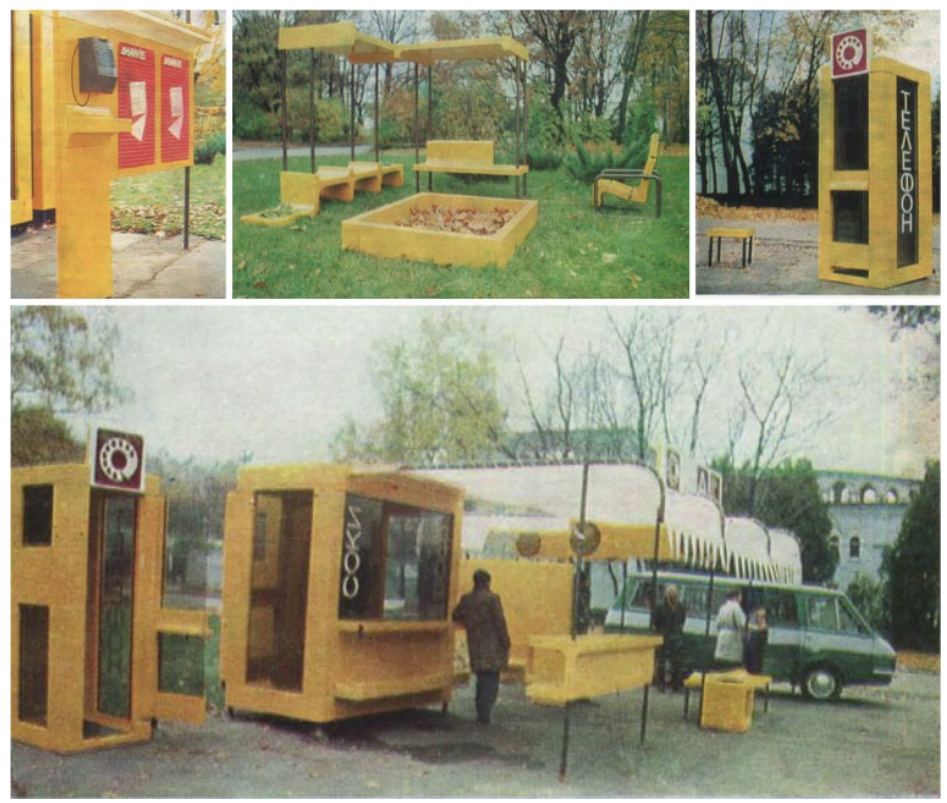

Fig. 3. $3^{\text {rd }}$ stage: the second half XXth century. Corporate identity as a universal project design method. Urban equipment for Digomi-7 (Tbilisi). Group example installation of equipment. Archive of the Moscow design museum.

\subsection{The fourth stage, late XXth - beginning of XXIst centuries. Personalization of corporate identity and branding}

The changes taking place in modern society in the context of its transition to the postindustrial stage were reflected in the further development of local artistic style education in design. Orientation towards a person and their individual characteristics and needs led at the end of the twentieth century to such phenomena in design as tuning, restyling, modding, facelifting - improvements and personification of serial samples of industrial products. The individualization of style education is reflected in the widespread design of the interiors of individual dwellings. The profession of a «designer-stylist», engaged in the design of the image and «style of a person», is also spreading.

De-massification of production and downsizing with bringing enterprises to micro-size will radically transform industrial technology - products are produced in small series with a focus on completely individual products. The corporate identity «evolves into a brand» [27], becoming a design tool in the process of branding [28]. In the end of the 1950s the development of corporate identity became, as the famous American designer George Nelson wrote, one of the tasks of systems design as a kind of coordinating design and art program, a system of principles of shaping, reflecting the features and forming the image of the company [29] (Fig.4). 


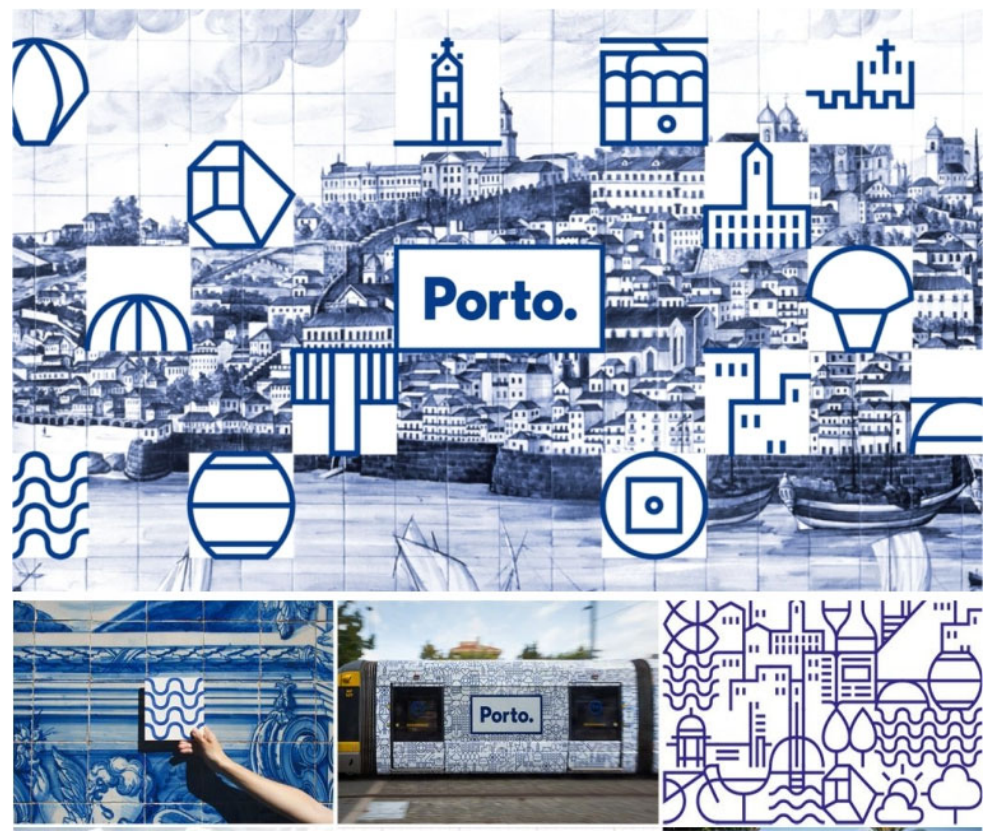

Fig. 4. $4^{\text {th }}$ stage: late XXth - beginning of XXIst centuries. Personalization of corporate identity and branding. City brand Porto.

\subsection{The concept of «local architectural and artistic style» of the urban ensemble}

The corporate styles that emerged in the bosom of industrial design found their way into the design of the urban environment in the second half of the twentieth century. One of the first forms of manifestation of corporate identity in the urban environment was the graphic accompaniment of such major public events as the Olympic Games, international exhibitions and festivals, within the framework of which universal systems of pictograms stylized and easily recognizable graphic images - became widespread. They entered the urban environment, becoming, along with other graphic elements, a system of brand names and symbols. A striking example is the 1968 Mexico City Olympics, where, in the face of a shortage of funds, instead of a large-scale construction of Olympic facilities, they relied on graphic and environmental design. The latter transformed Mexico City - decorated houses and streets, made the city functional, modern and understandable, created an atmosphere of a festive fiesta. The large-scale informational program of the Olympic identity included the design of the image of the XIX Olympiad and its promotion throughout the world.

The corporate styles of temporary events brought from outside were deliberately created in contrast to the historically established architectural environment of the city, introducing new figurative signs and symbols into it.

\subsection{Local architectural and artistic styles of pedestrian streets in the second half of XXth century}

The active construction of pedestrian streets in Western Europe began in the late 1950s 1960s in the conditions of mass restoration and reconstruction of the historical centers of cities destroyed during the Second World War and their adaptation to new transport conditions. The post-war euphoria of society, the desire for well-being and prosperity 
required an appropriate subject-spatial environment, including a higher level of comfort in urban spaces. At this time, a kind of «new wave» emerges in search of an «ideal city» (ideal urban environment). This new type of highly comfortable urban space has become a pedestrian street as an «ideal city of the XXth century», as a logical continuation of the centuries-old traditions of urban culture of Western European society, the beginning of which dates back to the Middle Ages, as a kind of «New Look» and a phenomenal phenomenon in post-war architecture and design [30].

When organizing the architectural environment of pedestrian streets, architects and designers turned to the romantic images of the medieval «City of Craftsmen» [30]. In a comfortable and relaxing environment of a multifunctional public center, which was a pedestrian street, the most striking traditional forms of social and cultural contacts have been revived and developed, and various new forms of social and cultural contacts have emerged.

The pedestrian street has become a unique experimental platform for the designer's large-scale work, which resulted in a «total synthesis» of design with various types of design and artistic activities. And what is very important, when organizing the spaces of pedestrian streets and their content, for the first time, an attempt was made to use the methods of ergonomics in organizing the spatial environment as a tool to increase its comfort. This was expressed in the shaping of outdoor furniture and equipment headsets (instead of the so-called small architectural forms), in the design of visual communication systems (instead of the inconsistency of traditional signs and advertising), in the development of font and color-graphic compositions, which were created taking into account the psychophysiology of human perception of information in urban space. Thus, in the design of pedestrian streets, for the first time, a fundamentally new approach to the organization of urban spaces was identified and the question of a new direction was raised «ergonomics of urban space» [30].

Especially noteworthy is the artistic and stylistic synthesis that has arisen in the design of pedestrian streets, based on the use of the method of «corporate styles», aimed at creating an individual architectural and artistic style within a single urban ensemble. The design of pedestrian streets has become an unprecedented phenomenon in the history of architecture and urban design, demonstrating for the first time that architectural and artistic stylistics in the design process can relate not only to an individual architectural building or a complex of buildings, but also to a significant urban ensemble, and at the same time have a sufficiently high degree of autonomy and independence from the so-called great historical art styles. The local architectural and artistic (corporate) style of the pedestrian street ensemble as a design method manifested itself in a whole multidimensional system (graphic style, color and light style, style of outdoor furniture and equipment headsets, etc.) [31].

\subsection{Local architectural and artistic style of the city quarter «Nikolayviertel» by the 1980s}

The historic St. Nicholas quarter in the center of Berlin can be considered as a classic example of the full-scale application of the corporate identity method in the architecture of the city. In 1987, for the 750th anniversary of Berlin, the reconstruction of the oldest quarter of the city, almost completely destroyed during the Second World War, was completed. The designers faced an ambitious task - to create a landmark facility in the capital of East Germany. The task of creating a vivid and memorable image of the ensemble was solved largely due to the active use of urban design tools that were new at that time. With the help of the latter, in the process of reconstruction and improvement, the designers have created their own (local) architectural and artistic style, a kind of «corporate style» of the urban ensemble, which makes it extremely holistic, semantically, stylistically, 
compositionally, coloristically, and information-rich, highlighting it as a special landmark in the structure of the city center.

In the center of the quarter is the Gothic Church of St. Nicholas (Nikolaikirche) - the oldest building in Berlin (1220-1230), around which a settlement arose, which later turned into Berlin. The Nikolaikirche is not only a compositional accent and a spatial reference point, but also a semantic dominant of the quarter, from which it takes its name. The authors of the project, continuing and emphasizing the medieval traditions of toponymy, gave the cafe located near Nikolaykirche the name Nikolaikafe, emphasizing the characteristic features of the place and significant objects located here and the names of the cafe «at the Rathaus Cafe», «under the Arcades» (Zu den Arkaden).

Most of the destroyed historical buildings of the quarter were demolished and new buildings were erected in its place during the reconstruction process. At the same time, the layout of the quarter remained as close as possible to the historical original. This western border of the quarter, overlooking the Spree, is considered as a gem of panel art: tourists are looking for the idyll of old Berlin here. The authors of the project expected the new building in a single color-textured range: the rich ocher-yellow color of the plastered first floors and the corrugated gray concrete panels of the residential buildings of the second and fourth floors. The preserved historical buildings were returned to their original polychrome. Thus, thanks to this solution, it was possible to visually combine the development of the quarter into an integral ensemble and at the same time create a sufficiently monotonous context for highlighting historically and artistically valuable architectural objects on it with «colored spots» (Fig. 5).

The «historical theme» received a special sound and development in landscaping, small architectural and sculptural forms, architectural details and equipment of facades, signboards and visual communications. Together with the polychrome facades of historical monuments, the «historical and architectural cut» of the ensemble was formed with the retro-forms of street lamps, billboards, water columns and wells, signboards and street paving, referring the viewer to the rich history of the unique place. Against the gray-yellow background of modern buildings, contrasting with their architecture, they become objects of perception, important elements of the general historical and architectural exposition.

The «historicism» in the architectural form of new objects in the oldest Berlin quarter is also supported by the theme of arcades, which became dominant in the architectural and artistic solution of the first floors of the quarter, and medieval tongs with a triangular end on the facades. The arched shape also symbolizes the historicism of the place, associating with the traditional shopping arcade of the old city. At the same time, made with the use of house-building technologies of second half of XXth century, stylized forms of arches and gables are modern and create a kind of stylistic bridge between the «old» and «new».

We also see historical motives in the solution of public spaces on the ground floors: the fine-mesh structure of stained-glass windows of shop windows filled with convex glass imitating medieval glassblowing technologies, awnings over the entrances and shop windows, which practically do not carry their former function of protection from the sun, having turned into a kind of decorative symbol indicating the commercial purpose of the buildings. A kind of historical game appears, but this game is played in the language of new technologies. Made of metal in emphatically «chopped» forms, these pseudo-marquises are modern, solved in a single structural module and style key, they unite the entire spatial ensemble, becoming another element of its local architectural and artistic style.

For tourists, the quarter became a unique place, a special attraction of Berlin, and its popularity was the evidence of this for more than a decade. Gunther Stann, the chief architect of the reconstruction of the quarter for the 750th anniversary of the city, explained his success in the competition among 26 participants as follows: his main idea was not a strict reconstruction and a return to the original medieval forms, but a desire to find a 
balance between modern residential buildings and only partially following the formative ideas of old buildings. The result is a hybrid form, a synthesis of the old and the new and, apparently, now also an attraction.

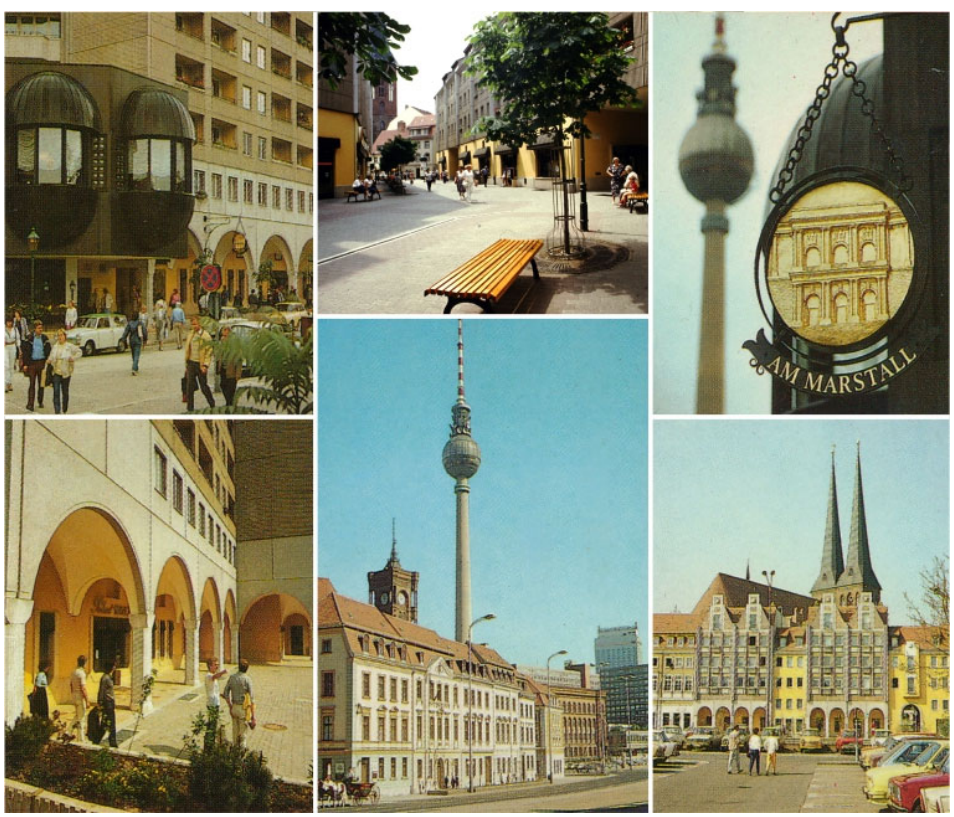

Fig. 5. Local architectural and artistic style of the city quarter «Nikolayviertel» by the 1980s.

The example of the reconstruction of Nikolayviertel in 1987 demonstrates that the method of corporate styles in the architecture of the city, forming the local architectural and artistic style of the ensemble, solves a fairly wide range of design tasks, among which the following can be distinguished:

1. Unification, based on the general concept of the local architectural and artistic style, of an ensemble of diverse objects into a spatially, artistically and stylistically integral ensemble.

2. The method of corporate styles allows architects and designers to work with unprecedentedly large objects in the territory, creating a holistic local architectural and artistic style for the street, quarter and even the city as a whole.

3. In comparison with the large historical architectural and artistic style, the local architectural and artistic style in the architecture of the city has a more «local» character and is aimed at increasing the expressiveness, individualization and uniqueness of the territorial entity (ensemble).

4. The local architectural and artistic style of the ensemble, relying mainly on design means, can be created in a fairly short time frame. At the same time, unlike the big historical one, on the one hand, it is more subjective (in the territorial aspect), reflecting the «laws of the place» (the spirit of the place), but at the same time it is more objective (in the temporal aspect), reflecting the same laws places.

5. The use of the method of corporate styles in architecture presupposes not only a new form of artistic synthesis in the form of a local architectural and artistic style of the ensemble, which is relatively permanent, but also to have temporary forms of its manifestation, such as corporate styles of decoration of holidays, major events and public events, political events. Being of a temporary nature, it can periodically change the appearance of the architectural ensemble, and as a result - enrich the collective image of the city. 
6. Corporate identity as a «memory of the place». In the practically rebuilt historic quarter in Berlin, mainly by means of design, the designers managed to «turn back the clock», create an open-air museum, a kind of monument to the oldest quarter of Berlin on the eastern bank of the Spree [32].

In 1987, a commemorative series of 4 coins in denomination of 5 marks was issued for the 750th anniversary of Berlin. One of them depicts Nikolayviertel. Thus, it was presented to the world community as one of the symbols-brands of the capital of eastern Germany.

\subsection{From the local architectural and artistic style of the ensemble to the territorial branding}

In the context of general global changes brought about by the post-industrial society, experts note the changes in the nature of the method of corporate styles, its evolution into brand and branding. The corporate style «surpasses itself: it is virtualized and reborn into a sign-symbol that exists independently of the real thing and many times surpasses and enhances its real material qualities» [27].

Formed in the conditions of the latest advertising and information technologies of the XXI century, the marketing direction of corporate identity, branding, is beginning to be used in relation to the city and even the region. The image of the city, «packed» in a kind of compact and communicative form, is considered here as an important factor in attracting financial, labor and other resources to its territory. In the purposeful creation of an attractive image of the place and its success in the market space, spiritual and social life, in the cultural and political sphere, a large number of specialists from various fields are involved, ranging from historians, archaeologists and local historians, ending with administrative, political and commercial circles. At the same time, design plays a special role here.

At this time, changes are taking place in the external appearance of Nikolayviertel, in which one can trace the evolution of the local architectural and artistic style created during the reconstruction of the second half of 1980s, into the modern brand of this unique historical place in Berlin. St. Nicholas begins to position itself as one of the most attractive places in the German capital. The quarter has its own website, a bright, memorable and very capacious graphic logo, placed in different parts of Berlin with the caption: «5 museums, 22 restaurants and cafes, 50 shops, culture, architecture and history of Berlin all in one block on the Spree!» [30]. At the same time, the graphic, artistic and stylistic accompaniment of the territorial branding of the architectural ensemble became a logical continuation and development of its local (corporate) architectural and artistic style, embedded in the architectural context, enhancing its imaginative component and general artistic «positive». (Fig. 6)

These changes are due, on the one hand, to the changes taking place in the postindustrial society in the context of a technological revolution and a change in value orientations. On the other hand, the unification of Germany led to a complete «restructuring» of the socialist system of the GDR with state ownership, planned economy and socialist values. Opinions about Nikolayviertel were divided and sometimes radically different from each other. Now «... some began to call Nikolayviertel» socialist Disneyland». But many people come here with pleasure» [31].

The color scheme of the background panel buildings has changed, the contrast has softened, the intensity of the ocher-yellow color of the first floors has changed to a calmer whitened grayish-yellow. The quarter, having lost its color, has become less dominant in the context of the center of Berlin [33]. 


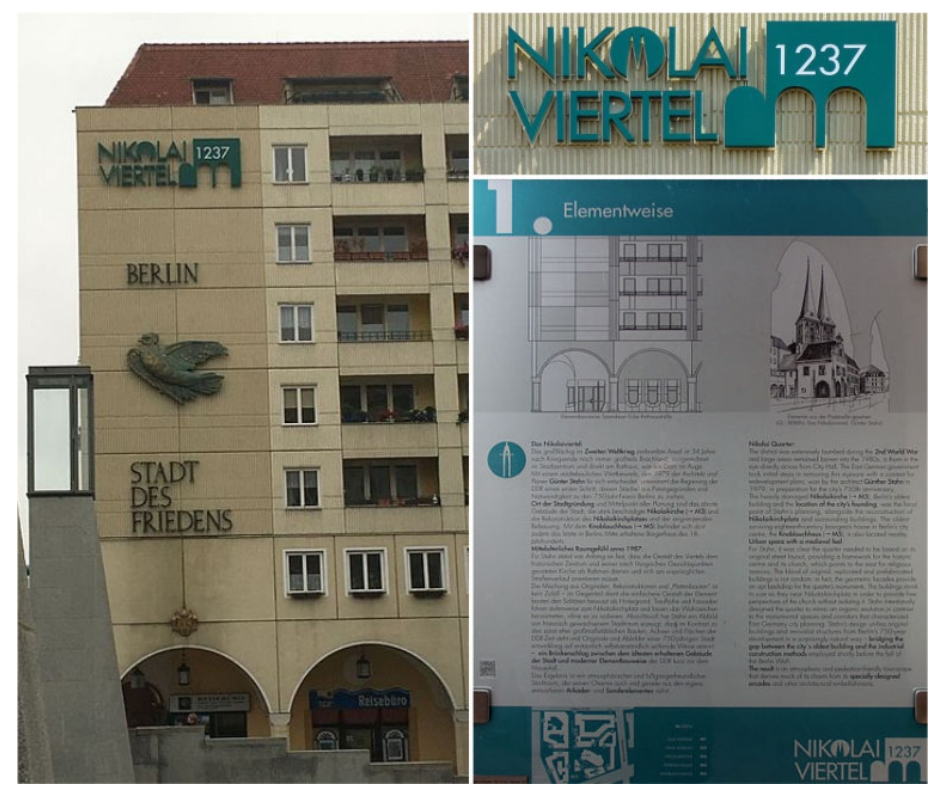

Fig. 6. From the local architectural and artistic style of the ensemble to the territorial branding.

\subsection{Modern shabby chic parsing}

In the course of its historical development, the village of Berlin of the XIII century, located on the banks of the Spree near the Nikolaikirche, turned in 1987 into the quarter of St. Nicholas, and then into one of the brands of Berlin - the capital of Germany. Moreover, the beginning of branding was laid by the issue of the commemorative coin «Berlin Nikolaiviertel» in 1987.

Nikolayviertel keeps pace with the times, and maybe even ahead of it, so changes in its appearance continue. Recently, a significant change in the color range has occurred again: the intense graycolor of the ribbed panels of residential buildings has disappeared, it has been replaced by strongly whitened (almost white) colors with light beige, gray-bluish and lilac shades. These colors appeared in place of the pronounced yellow and on the first floors of the building. As a result, the previously clearly marked and color-rich «town-planning parterre» now practically does not stand out in the spatial structure of the quarter [33].

In the conditions of private property, the absence of a general concept and principles of shaping elements of urban design, new signs and names have appeared and old signs and names have disappeared. There is no more «Nikolaykafe», the cafe «near the Town Hall», artificially created «medieval toponymy» today has no place. A medieval wall sundial over a walk-through arch in one of the courtyards is now difficult to distinguish among the wild grapes growing rapidly along the wall of a residential building. The root trellises of trees are not very neatly covered with rubble. Sometimes all this reminds of another example from the history of architecture - the ancient Roman palace of Diocletian in Split, the ruins of which were used by the medieval inhabitants of Salona simply as a building material. And in the walls of their buildings, along with stones, an ancient Roman capital turned upside down can be seen [31].

About today's St. Nicholas it is already difficult to speak of as a textbook example of the use of the method of «corporate styles» in the architecture of the city. The local architectural and artistic style of Nikolayviertel, conceived in socialist Germany, designed to create a unique place, one of the symbols of Berlin, has remained in the past, the oldest 
quarter, once emphasized in the spatial structure of the city center and turned into a Berlin brand, has now disappeared into the context of the urban «Mitte». As a symbol and brand of Berlin, it remained only on the 1987 coin. Instead of an «open-air museum» with a clearly organized historical and architectural exposition, the visitor is offered a «settled» and a little shabby in the "shabby chic» style urban environment with picturesque green corners of cafes and restaurants.

\section{Conclusion}

As studies show, a feature of style formation in design is high dynamics, relative fragility and transience in the change of artistic and stylistic trends, as well as their locality. And the maximum localization of the artistic and stylistic trend is the so-called «corporate identity», which is created by a specific author or group of authors for a specific (local) object - a company, or a specific event. Therefore, local art styles are clearly subjective in comparison with large and large historical styles.

The design coordination and corporate image, which emerged at the beginning of the last century, has become one of the leading design methods in the design of the twentieth century. Having passed more than a century's path of development, including a number of stages (from the first styles for large corporations, then as a widespread area of project activity and a universal method of design), corporate identity has grown into branding - a unique phenomenon of our time, spreading in various fields of human activity.

In the architecture of the city, the method of «corporate styles» manifested itself in the creation of «local architectural and artistic styles» of urban ensembles. Local architectural and artistic styles have become widespread in the organization of pedestrian streets in urban centers as a means of stylistic harmonization of a diverse architectural environment and increasing its integrity and artistic expressiveness. A textbook example of such a local architectural and artistic style is the reconstruction of 1985-1987. Nikolayviertel is the oldest quarter in the center of Berlin. One can observe how, over more than 30 years of history, the local architectural and artistic style of Nikolayviertel has grown into its territorial brand, within which the historic quarter begins to position itself as one of the most attractive places in the German capital. At the same time, the graphic and artistic and stylistic accompaniment of territorial branding became a logical continuation and development of its local architectural and artistic style, embedded in the architectural context, enhancing its imaginative component and the general artistic «positive». The modern post-industrial society brings with it changes that have affected the artistic and aesthetic qualities of the environment. And instead of an «open-air museum» with a clearly organized historical and architectural exposition, the visitor is offered an «inhabited» and slightly shabby in the «shabby-chic» style urban environment with picturesque green corners of cafes and restaurants.

\section{References}

1. V.L. Glazychev, Design as it is (Moscow, Europa, 2006)

2. J. Lang, Urban Design: A Typology of Procedures and Products (Oxford, Architectural Press)(2005)

3. H. Fraker, Street, parks and houses: Case study of a pedestrian neighbourhood Future visionsof urban public housing (2017)

4. M.G.H. Lunecke, R. Mora, The layered city: Pedestrian networks in downtown Santiago and their impact on urban vitality, Journal of Urban Design, 23(3) (2018) DOI: 10.1080/13574809.2017.1369869 
5. Z. Lin, Vertical urbanism: Re-conceptualizing the compact city, Vertical urbanism: Designing compact cities in china (2018) DOI: 10.4324/9781351206839

6. E.Macdonald, Innovative street design in a city without freeways: The case of Vancouver, Journal of Urban Design, 24(5) (2019) DOI: 10.1080/13574809.2019.1568863

7. S. Cozzolino, J. Polivka, R. Fox-Kamper, M. Reimer, O. Kummel, What is urban design? A proposal for a common understanding, Journal of Urban Design, 25(1) (2020) DOI: 10.1080/13574809.2019.1705776

8. F. Racine, The influence of urban design theories in the transformation of urban morphology: Montreal from 1956 to 2018, Journal of Urban Design, 24(6) (2019) DOI: 10.1080/13574809.2019.1601994

9. V. Tikhov, A. Shifman, Design aspect of the formation of micro-spaces in urban environment, Praxema, 2019(2) (2019) DOI: 10.23951/2312-7899-2019-2-152-159

10. R. Silva-Roquefort, F. Munoz, Urban ergonomics as an adaptative strategy of public space. A critical analysis of the current urban paradigm Bitacora Urbano, Territorial 29(2) (2019) DOI: 10.15446/bitacora.v29n2.70141

11. J. Lang, Urban design: A typology of procedures and products: Illustrated with over 50 case studies (2017) DOI: 10.4324/9781315642406

12. S. B. D.Goldberg-Miller, Planning for a city of culture: Creative urbanism in Toronto and New York (2017) DOI: 10.4324/9781315309255

13. E. Bulgakova, K. Lidin, The latest trends vs urban environment, Project Baikal (2019)

14. A. Remesar, From sculpture to post-muralism. public art policies in urban regeneration processes On the W@terfront, 61(1) (2019) DOI: 10.1344/waterfront2019.61.6.1

15. S. Marshall, The kind of art urban design is, Journal of Urban Design, 21(4) (2016) DOI: 10.1080/13574809.2015.1133226

16. L. Alessio, Public open space design in Tokyo urban environment: A historical overview, Territorio, 91 (2019) DOI: 10.3280/TR2019-091014

17. J. Kim, Designing multiple urban space: An actor-network theory analysis on multiplicity and stability of public space, Journal of Urban Design, 24(2) (2019) DOI: 10.1080/13574809.2018.1468214

18. L. Giraldi, E. Benelli, R. Vita, I. Patti, J. Filieri, F. Filippi, Designing for the next generation. children urban design as a strategic method to improve the future in the cities, Design Journal, 20(1) (2017) DOI: 10.1080/14606925.2017.1352814

19. R. Alvarez, F. Duart, Spatial design and placemaking: Learning from video games Space and Culture, 21(3) (2018) DOI: 10.1177/1206331217736746

20. F. Armato, Pocket park: Product urban design, Design Journal 20(sup1)(2017)

21. J. Borland, Small parks, big designs: Reconstructed Tokyo's new green spaces, 19231931, Urban History, 47(1) (2020) DOI: 10.1017/S0963926819000567

22. A. Figliola, Post-industrial robotics: The new tendency of digital fabrication for exploring responsive forms and materials through performance, ArchiDOCT, 4(2) (2017)

23. A. Markopoulou, Smart who? collective intelligence urban design models, Architectural Design, 90(3) (2020) DOI: 10.1002/ad.2578

24. L Merino Sanjuan, M. Puyuelo Cazorla, M. Val Fiel, Design for the smart cities. investigation about citizen's needs and products to improve public places, Design Journal, 20(1) (2017) DOI: 10.1080/14606925.2017.1352979

25. A. A. Dembich, N. G. Orlova.Features of preserving the historical and cultural identity of large industrial cities (on the example of Naberezhnye Chelny). Izvestiya KGASU, 3(53) (2020) 
26. G. N. Aidarova-Volkova. Potential for complex detection, conservation and tourist use of Kazan's architectural heritage in the context of sustainable development of the historical center, Izvestiya KGASU, 2(48) (2019)

27. I. E. Schetchikov, Evolution of corporate identity in the design culture of the 20th century, Abstract of the dissertation of the PhD in Art History(2005)

28. N. D. Dembich, S. M. Mikhailov, Evolution of the concept of "Corporate identity», Design revue, 2012(1-2)(2012)

29. J. Nelson, Design Problems(Moscow, Art, 1971)

30. S. M. Mikhailov, A. S. Mikhailova, N. M. Nadyrshine, Multilinear approach to representing the historical evolution of urban design (industrial and post-industrial periods), IOP Conference Series: Materials Science and Engineering, 890, 012006 (2020) DOI: 10.1088/1757-899X/890/1/012006

31. S. M. Mikhailov, A. S. Mikhailova, Urban design-city design (evolution of methods of organization of the subject-spatial environment), Architecture and construction of Russia, 4(228) (2018)

32. S. M. Mikhailov, Dizajnsovremennogogoroda: kompleksnayaorganizaciyapredmetnoprostranstvennojsredy (teoretiko-metodologicheskayakoncepciya), Abstract of the dissertation of the Doctor of Art History, 2011)

33. S. M. Mikhailov, A. S. Mikhailova, R. R. Khafizov, N. M. Nadyrshine, L. I. Nadyrshine, Supergraphics as a project and artistic method in design of a modern city, IOP Conference Series: Material Science and Engineering, 890, 012003(2020) DOI: 10.1088/1757-899X/890/1/012003 